\title{
Effective human resource management strategy for hospital nursing organizations
}

\author{
Ayana Matsumoto ${ }^{\mathbf{a}^{*}}$
}

${ }^{a}$ St. Luke's International University, Graduate School of Nursing Science, Tokyo, Japan

CHRONICLE A B S T RACT

Article history:

Received: October 18, 2018

Received in revised format: November 26, 2018

Accepted: November 26, 2018

Available online:

November 27, 2018

Keywords:

Human resource management

Nursing

Staff development

Magnetism

\begin{abstract}
Human resource management (HRM) was first developed as a corporate business strategy that aimed to retain employees in the workplace and to develop personnel who generated results and whose capabilities could be effectively utilized. In recent years, human resource perspectives have been emphasized in personnel management by hospital nursing organizations. This study examined effective HRM strategies for creating an attractive nursing practice environment from the perspective of "magnetism." A questionnaire ("32 Items Regarding Effective Human Resource Management Policies") was developed. The Practice Environment Scale of the Nursing Work Index was employed to assess the type of environment in which nurses wished to continue working, and factors contributing to a desirable nursing practice environment were defined as "magnetic." Analysis of data obtained from nursing managers $(n=305)$ yielded five factors that were effective HRM policies for hospital nursing organizations. It was also shown that the nursing practice environment was made more attractive by incorporating more of these policy elements. The following six strategies were identified: (1) enhancement of personal career development and organizational development; (2) goal management and personnel evaluations to assure the quality of patient care and promote team collaboration; (3) flexible hiring and transfer policies based on business execution; (4) promoting outside interactions to make the organization an open system; (5) ensuring support for career development; and (6) supporting a safe and healthy nursing practice environment by enhancement of manpower.
\end{abstract}

C 2019 by the authors; licensee Growing Science, Canada

\section{Introduction}

Human resource management (HRM) begins with a corporate business strategy in an effort to retain employees in the workplace and develop them into personnel who generate results and whose capabilities can be utilized effectively (Tyson, 1995). Research on strategic human resource utilization has been conducted globally and many results have been reported (Brown et al., 2012; Francis \& Keegan, 2006). In recent years, research on human resource development in nursing has been conducted in various countries (Karimi et al., 2005; Lammintakanen et al., 2008). There have been reports that nursing organizations should establish strategies on the basis of financial and managerial resources, managerial positions, and organizational culture (Kim et al., 2018). Nursing organizations have also accepted that strategic management of personnel is important.

\footnotetext{
* Corresponding author. Tel. : +81-3-5550-2372

E-mail address: m-ayana@slcn.ac.jp (A. Matsumoto)

(C) 2019 by the authors; licensee Growing Science, Canada doi: $10.5267 /$ j.msl.2018.11.015
} 
In Japan, more effective management of human resources by hospital nursing departments is of particular interest (Watanabe, 2002). If hospitals position nurses as important human resources for achieving hospital targets, establish them in the workplace, and assist their development, this will achieve better results and have benefits for nursing outcomes. Thus, a human resource perspective has been emphasized in personnel management by hospital nursing organizations in Japan.

Nurses realize that nursing practice is an organizational outcome, and further development of nursing ability can result in a more attractive workplace. Therefore, it is important to conduct HRM of the nursing department from the viewpoint of effective use of human resources, and create an organization that is easy for nurses to maintain.

Against this background, various effective HRM strategies have been developed in the nursing field in Japan, mainly in hospital nursing departments. Improvements have been made to motivation, etc. through career development models (Hirai, 2002) and skills development (Kashiwagi, 2006; Uchiba et al., 2008; Yokoyama et al., 2005), while some authors have advocated improving the work environment based on surveys of actual nursing conditions (Izukami, 2007).

These efforts are aimed at personnel management that develop nurses who can do more things more effectively. At the same time, it can be observed that such efforts contribute to a feeling of personal reward for nurses and improve workplace stability. Thus, personnel management that sees nurses as human resources is not only beneficial for achieving hospital goals, but also creates an attractive nurse practice environment in which nurses wish to continue working.

In research on organization established by nurses in hospital, Kramer and Hafner (1989) defined organizational characteristics common to hospitals that have succeeded in securing and establishing nursing jobs in the United States, explaining these characteristics as "magnetism" that was evaluated based on 14 items.

In this study, we had two objectives. One was to perform structural analysis of the relationship between HRM policies of hospital nursing groups and the nursing practice environments from the perspective of "magnetism." The other was to examine effective HRM policies for creating an attractive nursing practice environment based on the results of the structural analysis.

We defined "effective HRM policies for hospital nursing organizations" as methods of managing people to build a nursing practice environment using "magnetism", while an "attractive nursing practice environment" was defined as a nursing practice environment based on "magnetism" that attracts nurses like a magnet.

\section{Methods}

\subsection{Study Design}

This was an exploratory descriptive study that examined the relationship between HRM policies implemented by the nursing managers at hospitals and an attractive nursing practice environment using statistical methods.

\subsection{Instruments}

First, a list of HRM policies employed by the nursing departments of hospitals was created. Questions were prepared with reference to the three factors of HRM measures indicated in the results of prior research in the field of management behavior science (Shin, 2002). Shin (2002) stated that employees are part of two overlapping commitment structures, organizations and jobs, and that human resource 
policies aimed at these two overlapping commitments are most effective. Shin also presented three factors that should inform policies: 1) enabling ways to deepen expertise, 2) meritocracy and hiring, and 3) planned career development. Nurses belong to organizations, but at the same time seek out activities as specialists. This can be understood as having overlapping commitments to an organization and to a job. Therefore, the present study used the conceptual framework of "effective HRM policies for hospital nursing organizations." In accordance with the nine items in the three-factor subscales proposed by Shin, 36 items were devised with regard to HRM policies for nursing organizations. Pretesting and detailed analysis were performed with six nursing managers, and the content and surface validity of the questionnaire were confirmed. The 32 items shown to be valid were then used as policy items. Because an attractive nursing practice environment in which nurses want to continue working is considered to possess "magnetism", the outcomes of "effective HRM policies for hospital nursing organizations" were measured by using the Japanese version (Ogata et al., 2008) of the "Practice Environment Scale of the Nursing Work Index" (PES-NWI) (Kramer \& Schmalenberg, 2005) that was specifically developed for assessment of nursing practice environments.

\subsection{Data Collection}

The survey was mailed to nursing managers with a request for practice-level responses to the $32 \mathrm{HRM}$ policy items. Responses to the Japanese version of PES-NWI were requested as "results of policies you have put into practice.” Data were collected between June 1 and September 30, 2010.

\subsection{Setting and Samples}

The targets of the survey were the heads of nursing organizations (nursing managers) at hospitals in Japan with 300 or more beds. A total of 1,128 domestic hospitals matching the criteria (as of July 2010) were divided into seven geographic regions, and 730 hospitals were then randomly selected by a stratified extraction method. An anonymous self-answered questionnaire was sent to these hospitals. This questionnaire included questions regarding the attributes of the nursing manager and hospital, 32 items related to HRM policies, and 31 items for the Japanese version of PES-NWI.

\subsection{Data Analysis}

PASW Statistics version 17 was used for data analysis. Causal analysis (principal component analysis using the Promax method in conjunction with Kaiser normalization) was conducted for data on HRM policies and PES-NWI, with extraction of constituent factors and calculation of a reliability coefficient (Cronbach's $\alpha$ coefficient). Amos 17.0 was used for path analysis. HRM policy factors were employed as independent variables, whereas PES-NWI factors were used as the dependent variables. Subsequently, regression analysis was carried out. One-way analysis of variance (ANOVA) was performed to assess the attributes of nursing managers and hospitals along with each constituent factor, followed by the unpaired $t$-test. Multiple comparisons were performed with Tukey's honest significant difference method.

\subsection{Ethical Considerations}

This study was approved by the St. Luke's International University Research Ethics Review Committee at the planning stage (Approval no. 10-014).

\section{Results}

A total of 338 responses were received (response rate: $46.3 \%$ ), but 33 were excluded because of not meeting the criteria for research subjects and the remaining 305 were used for analysis (effective response rate: 41.7\%). Most of the 305 nursing managers in our sample were in their $50 \mathrm{~s}(\mathrm{n}=262$, 
$85.9 \%)$. The highest completed level of education was specialist nursing school graduate $(\mathrm{n}=202$, $66.3 \%)$, followed by university graduate $(\mathrm{n}=50,16.4 \%)$, graduate school master's degree $(\mathrm{n}=32$, $10.6 \%)$, and graduate doctorate degree $(n=2,0.3 \%)$.

\section{Table 1}

Five factor patterns identified by causal analysis of HRM policies

\begin{tabular}{|c|c|c|c|c|c|c|}
\hline \multirow{2}{*}{ Policy No. } & \multirow{2}{*}{ Details } & \multicolumn{5}{|c|}{ Component } \\
\hline & & 1 & 2 & 3 & 4 & 5 \\
\hline \multicolumn{7}{|c|}{ Factor 1: Personal career development and organizational development } \\
\hline 32 & $\begin{array}{l}\text { Transfer of nursing department nurses according to a proper personnel de- } \\
\text { ployment plan, with no group bias toward nursing characteristics. }\end{array}$ & .71 & -.15 & -.11 & .12 & .02 \\
\hline 31 & $\begin{array}{l}\text { The head nurse is supportive in promoting the personal career orientation of } \\
\text { nurses. }\end{array}$ & .66 & -.24 & .05 & .02 & .12 \\
\hline 1 & $\begin{array}{l}\text { There are internal training programs for each stage of a nurse's career (includ- } \\
\text { ing associate nurses). }\end{array}$ & .64 & -.05 & -.10 & .22 & -.17 \\
\hline 29 & $\begin{array}{l}\text { There is a system that allows career-building in line with the personal circum- } \\
\text { stances of nurses. }\end{array}$ & .63 & -.04 & .12 & -.21 & .18 \\
\hline 17 & $\begin{array}{l}\text { Data are collected to provide a basis for hiring nurses with the specialized } \\
\text { skills needed to achieve organizational goals. }\end{array}$ & .62 & .05 & .02 & -.39 & -.11 \\
\hline 21 & $\begin{array}{l}\text { There is a system for development of problem-solving skills through collabo- } \\
\text { ration between nurses and other staff in the hospital. }\end{array}$ & .59 & -.03 & .02 & .06 & .00 \\
\hline 25 & $\begin{array}{l}\text { There is a system that allows newly developed nursing skills to be propagated } \\
\text { within the hospital. }\end{array}$ & .55 & -.01 & -.04 & .17 & .18 \\
\hline 28 & $\begin{array}{l}\text { There is a system to support the training of nurses in new techniques and } \\
\text { knowledge when their career plans change. }\end{array}$ & .54 & .05 & -.05 & .10 & .30 \\
\hline 5 & $\begin{array}{l}\text { Internal training programs can be selected according to personal skills and in- } \\
\text { terests and are not the same for everyone. }\end{array}$ & .53 & .08 & .00 & .22 & -.09 \\
\hline 10 & $\begin{array}{l}\text { A structure is available for exchange of ideas and consultation with experts } \\
\text { outside the hospital, so that nurses can solve practical problems and issues. }\end{array}$ & .51 & .09 & -.02 & .04 & .15 \\
\hline 11 & $\begin{array}{l}\text { Using computer search engines and the latest nursing books and journals, } \\
\text { nurses are able to access the latest nursing information. }\end{array}$ & .50 & .02 & -.16 & .24 & -.03 \\
\hline 18 & $\begin{array}{l}\text { Assessors are trained to assess the achievements of nurses based on organiza- } \\
\text { tional goals. }\end{array}$ & .48 & .34 & .01 & -.32 & -.15 \\
\hline 9 & $\begin{array}{l}\text { There is a system for nurses to implement outstanding nursing practice within } \\
\text { the hospital (regardless of certifications). }\end{array}$ & .43 & .10 & .19 & .23 & -.01 \\
\hline \multicolumn{7}{|c|}{ Factor 2: Goal management and personnel evaluation } \\
\hline 24 & $\begin{array}{l}\text { There is a system to reflect assessment of the achievement of hospital organi- } \\
\text { zational goals during personnel evaluation. }\end{array}$ & -.05 & .87 & .01 & -.03 & -.05 \\
\hline 4 & Nursing salaries are based on personnel evaluation. & -.21 & .86 & -.11 & .09 & .18 \\
\hline 20 & $\begin{array}{l}\text { There is a system to assess the quality of work based on detailed personnel } \\
\text { evaluation rather than on attitude. }\end{array}$ & -.02 & .81 & .06 & .09 & .01 \\
\hline 27 & $\begin{array}{l}\text { There is a system to assess the degree to which goals are achieved and the } \\
\text { outcome is reflected by compensation. }\end{array}$ & -.11 & .73 & .03 & -.14 & .18 \\
\hline 12 & $\begin{array}{l}\text { Personnel evaluation is based on nursing capabilities expected by the organi- } \\
\text { zation. }\end{array}$ & .05 & .73 & -.07 & .12 & -.11 \\
\hline 19 & $\begin{array}{l}\text { There is a system to evaluate the performance of nurses based on organiza- } \\
\text { tional skills and performance is reflected in promotion. }\end{array}$ & .35 & .47 & .12 & .06 & -.21 \\
\hline \multicolumn{7}{|c|}{ Factor 3: Flexible hiring and transfer } \\
\hline 15 & $\begin{array}{l}\text { Transfer of nurses because of personal circumstances can be done in a flexi- } \\
\text { ble fashion. }\end{array}$ & -.03 & -.09 & .83 & .04 & .02 \\
\hline 6 & There is a system for hiring emergency nurses to manage hospital operations. & -.19 & .10 & .72 & .23 & -.04 \\
\hline 16 & $\begin{array}{l}\text { The personal career orientation of each nurse is respected, and departmental } \\
\text { transfers are done according to the wishes of each nurse. }\end{array}$ & .08 & -.04 & .70 & -.11 & .06 \\
\hline \multicolumn{7}{|c|}{ Factor 4: Promotion of external interactions } \\
\hline 2 & $\begin{array}{l}\text { Nurses are encouraged to participate in conferences and seminars outside the } \\
\text { hospital. }\end{array}$ & .18 & .05 & -.04 & .67 & .04 \\
\hline 8 & $\begin{array}{l}\text { Nursing heads (mid-level managers who directly manage the nurses in a nurs- } \\
\text { ing organization) are encouraged to participate in conferences and seminars } \\
\text { outside the hospital. }\end{array}$ & .15 & -.01 & .07 & .66 & .06 \\
\hline 7 & $\begin{array}{l}\text { Lecturers (including those from outside the nursing field) are invited from } \\
\text { outside the hospital if they are the best fit for nurse training. }\end{array}$ & .12 & .06 & .28 & .43 & -.07 \\
\hline \multicolumn{7}{|c|}{ Factor 5: Assurance of career development } \\
\hline 3 & $\begin{array}{l}\text { A leave of absence system that allows nurses to utilize training for entering } \\
\text { graduate school or acquiring certification. }\end{array}$ & .12 & .07 & -.12 & .08 & .72 \\
\hline 26 & $\begin{array}{l}\text { Nurses receive financial support for costs related to training for entering grad- } \\
\text { uate school or acquiring certification. }\end{array}$ & .01 & -.11 & .18 & .02 & .69 \\
\hline \multirow[t]{2}{*}{30} & Nursing expertise (professional certified nurses) is reflected by compensation. & .05 & .35 & .01 & -.09 & .48 \\
\hline & $\begin{array}{l}\text { Cause extraction method: Principal component analysis } \\
\text { Rotation method: Romax using Kaiser normalization }\end{array}$ & & & & & \\
\hline
\end{tabular}

HRM, human resource management.

After four items that showed low commonality and factor loading levels were removed, the third causal analysis revealed a cumulative contribution rate of $49.8 \%$. The following five factors ("five elements of HRM policies") were identified: (1) personal career development and organizational development, (2) goal management and personnel evaluation, (3) flexible hiring and transfer, (4) promotion of external interactions, and (5) assurance of career development (Table 1). Cronbach's $\alpha$ for these policy items was 0.88 , indicating a high degree of internal consistency. 
The mean value of each of the 31 PES-NWI items (on a four-point Likert scale) ranged from 2.29 [standard deviation (SD) \pm 0.79 ] to 3.53 (SD, \pm 0.64 ). In accordance with prior research (Kramer \& Hefner, 1989), causal analysis was conducted using a five-factor structure in this study. Commonality was in the range between 0.26 and 0.72 , and the eigenvalues were 1.2 or more for the five-factor structure. Excluding seven items with factor loadings of 0.4 or less, causal analysis was performed twice with the remaining 24 items and a cumulative contribution rate of 54.7\% was confirmed. Cronbach's $\alpha$ of the five factors was 0.90 , ranging between 0.68 and 0.80 for each individual factor. When the PESNWI factors were originally developed (Kramer \& Schmalenberg, 2005), the overall Cronbach's $\alpha$ was 0.90 and Cronbach's $\alpha$ for the subscales ranged between 0.71 and 0.83 , being very similar to the results of this study. The five factors were named the "five PES-NWI elements" and were defined as follows: (a) demonstration of powerful leadership by nursing managers, (b) quality assurance when providing patient care, (c) team collaboration and equality, (d) providing opportunities for career advancement, and (e) nurse participation in approvals and organizational decision-making. The overall composition of these factors was confirmed to be very similar to the PES-NWI factors reported in previous studies (Table 2) (Lake, 2002, 2007; McCusker et al., 2004; Chiang \& Lin, 2009).

\section{Table 2}

Previous research on the PES-NWI factor structure identified by this study

\begin{tabular}{|c|c|c|c|c|}
\hline & Lake $(2002,2007)$ (English) & $\begin{array}{l}\text { McCusker et al. (2004) } \\
\text { (French) }\end{array}$ & $\begin{array}{c}\text { Chiang and Lin (2008) Taiwan } \\
\text { (Chinese) }\end{array}$ & Matsumoto (2010) \\
\hline Factor 1 & $\begin{array}{l}\text { Participation in hospital } \\
\text { affairs }\end{array}$ & Participation in hospital affairs & Participation in hospital affairs & $\begin{array}{c}\text { Nurse participation in approval } \\
\text { and organizational } \\
\text { decision-making }\end{array}$ \\
\hline Factor 2 & $\begin{array}{l}\text { Nursing foundations for } \\
\text { quality of care }\end{array}$ & $\begin{array}{l}\text { Nursing foundations for quality } \\
\text { of care }\end{array}$ & Nursing quality & $\begin{array}{l}\text { Providing opportunities for } \\
\text { career advancement }\end{array}$ \\
\hline Factor 3 & $\begin{array}{c}\text { Nursing manager ability, } \\
\text { leadership, and support of } \\
\text { nurses }\end{array}$ & $\begin{array}{l}\text { Nursing manager ability, } \\
\text { leadership, and support of } \\
\text { nurses }\end{array}$ & Management and leadership & $\begin{array}{c}\text { Demonstration of powerful } \\
\text { leadership by nursing managers }\end{array}$ \\
\hline Factor 4 & $\begin{array}{c}\text { Staffing and resource ade- } \\
\text { quacy }\end{array}$ & Staffing and resource adequacy & Staffing and resource adequacy & $\begin{array}{l}\text { Quality assurance in providing } \\
\text { patient care }\end{array}$ \\
\hline Factor 5 & $\begin{array}{c}\text { Collegial nurse/physician } \\
\text { relations }\end{array}$ & $\begin{array}{c}\text { Collegial nurse/physician } \\
\text { relations }\end{array}$ & $\begin{array}{c}\text { Nursing professional devel- } \\
\text { opment }\end{array}$ & Team collaboration and equality \\
\hline
\end{tabular}

PES-NWI, Practice Environment Scale of the Nursing Work Index.

To investigate the relationship between the "five elements of HRM policies" and the "five PES-NWI elements," regression analysis was performed by using the scores for each policy element as independent variables and the PES-NWI item scores as dependent variables, and partial regression coefficients were calculated (Fig. 1). As a result, Policy 1 was shown to have a significant impact on all of the PESNWI elements. After developing a causal model and conducting path analysis, the path coefficient was found to be 0.84 , indicating that the nursing practice environment became more attractive as these policy elements were implemented more effectively (Fig. 2).

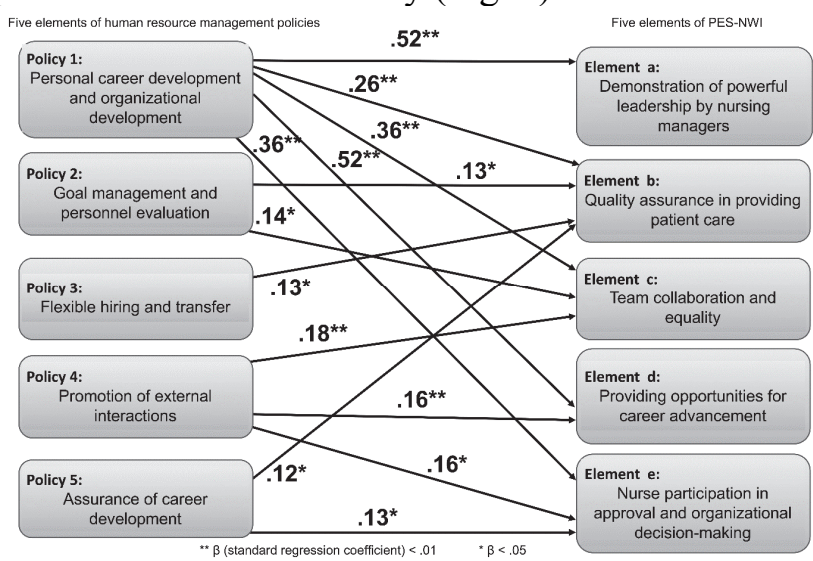

Fig. 1. Five elements of HRM policies and five elements of PES-NWI: Regression analysis of the elements. HRM = human resource management; PES-NWI = Practice Environment Scale of the Nursing Work Index. 


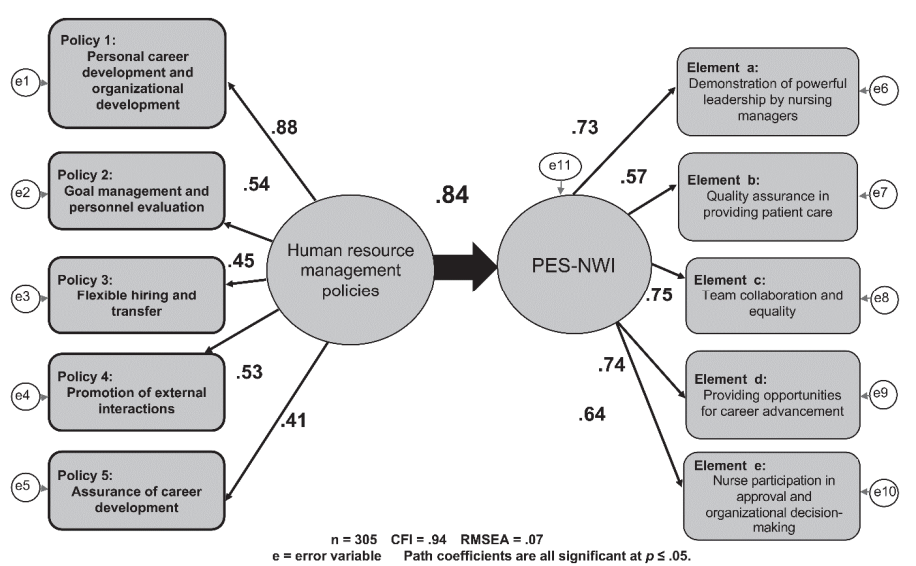

Fig. 2. Causal model of HRM policies and PES-NWI. HRM = human resource management; PES-NWI = Practice Environment Scale of the Nursing Work Index; RMSEA = root mean square error of approximation.

Then the following points were confirmed by statistical analysis of the relationship between hospital attributes and the five elements of HRM policies and five PES-NWI elements. The educational background of nursing managers was classified into three groups. For each element, one-way ANOVA and multiple comparisons were conducted for the mean item scores [implementation of Policy 1: Personal career development and organizational development $(\mathrm{F}(2,290)=8.14, p<.01)$; implementation of Policy 3: Flexible hiring and transfer $(\mathrm{F}(2,298)=6.80, p<.01)]$. It was shown that implementation of Policy 1 had greater significance $(p<.05)$ for respondents with a master's degree or higher and those with a bachelor's degree than for those who graduated from specialist nursing schools or junior colleges. Implementation of Policy 3 had greater significance $(p<.01)$ for respondents with a master's degree or higher than for those with a bachelor's degree and those who graduated from specialist nursing schools or junior colleges. When the unpaired $t$-test was conducted to compare each element with respect to the mean item scores for "certified nursing managers" and "others," implementation of Policy 1 was significant for "certified nursing managers" $(\mathrm{t}=-2.59, p<.05)$. After development of a causal model and conducting path analysis (Fig. 3), it was found that Policy 1 and all PES-NWI elements have a significant impact when nursing managers have an educational background of a master's degree or higher and also when they are certified nursing managers.

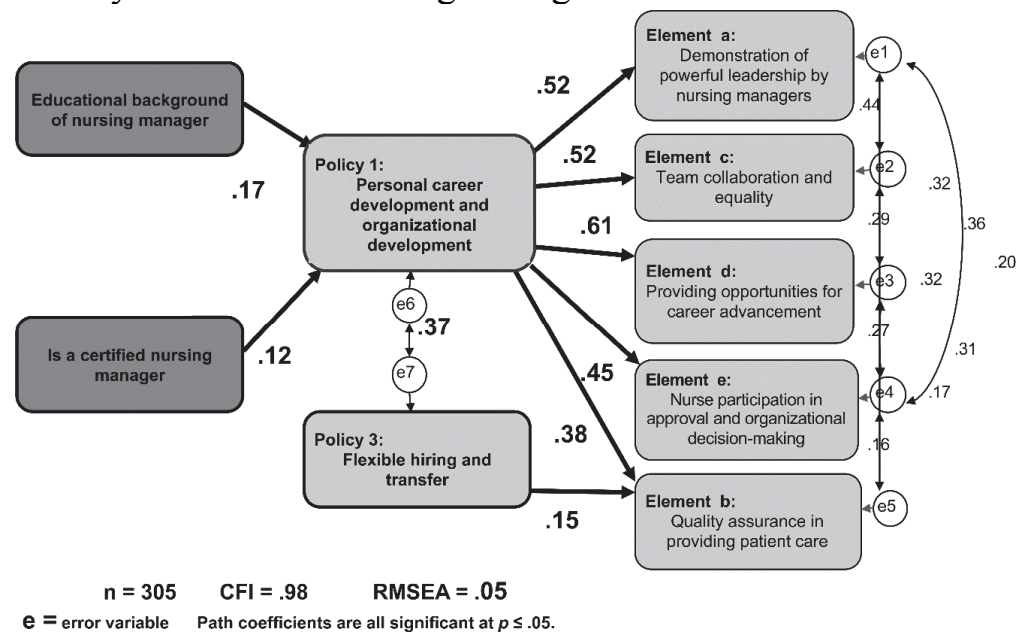

Fig. 3. Path model for attributes of nursing managers and elements of HRM, human resource management policies, and PES-NWI. CFI = comparative fit index; HRM = human resource management; RMSEA $=$ root mean square error of approximation . 
The unpaired $t$-test was conducted for each element with respect to the mean item scores for nurse:patient ratios of "7:1" and "about 7:1." As a result, "7:1" and "about 7:1" were both significant for policies $1,2,3$, and $4(t=3.00, p<.01 ; t=2.01, p<.05 ; t=3.56, p<.01$; and $t=2.09, p<.05$, respectively). In addition, "7:1" and "about 7:1" were significant for PES-NWI elements $\mathrm{b}$ and $\mathrm{d}(t=6.13, p<.01$; and $t=3.27, p<.01$, respectively).

\section{Discussion}

Based on the relationship structure of each element, the following strategies were identified for providing more effective HRM to create an attractive nursing practice environment.

This policy has a significant impact on all elements for creating an attractive nursing practice environment and is central to HRM. Enhancing implementation of this policy will have the greatest effect on creation of an attractive nursing practice environment. Schein (1978) stated that balancing organizational demands with personal demands is central to career development. The present study also showed the importance of a work environment that allows career advancement for nurses. The issues are 1) how nurses are treated as human resources, 2) how they are utilized by the organization, and 3) how career development is accomplished in this context.

Specific policies include "internal training programs for each stage of a nurse's career" and "a system that allows career-building in line with the nurse's personal circumstances."

In addition, the attributes with an impact on implementation of these policies or elements a, c, and d of an attractive nursing practice environment under "educational background of the nursing manager" demonstrated that this is a characteristic of "magnet" hospitals. Since 2008, a higher academic qualification has been required for nursing managers, with the education level of nursing managers being a criterion when applying for magnet hospital certification. Educational leadership by nursing unit managers has also been reported to improve the performance of nursing organizations (Choi et al., 2018). A similar trend was revealed by this study, and nursing managers thinking about their own career development was identified as an issue.

Based on the behavioral science theories of Drucker (1954), goal management has been proposed as a management method that simultaneously achieves both organizational and personal goals. In recent years, a growing number of hospitals have designed their personnel and wage systems on the basis of goal management (Watanabe, 2002).

This policy has a significant impact on elements $\mathrm{b}$ and $\mathrm{c}$ for creating an attractive nursing practice environment. This shows that nursing practices that strive for organizational goals ensure the quality of patient care and promote collaboration and equality among hospital teams. In addition, the present results suggested that this policy is made more effective by its strong correlation with personal career development and organizational development.

Regarding specific policies, examples include "a system to assess achievement of hospital organizational goals during personnel evaluation" and "a structure to assess the achievements of nurses based on organizational goals and that is reflected in promotion."

Western organizations identify personnel requirements, and base hiring and placement on specific business plans and needs (Tejima \& Ibe, 2009). Watanabe (2002) argued that flow resources should be utilized for hiring and placement based on specific business plans and needs in addition to core human resources. This type of business-based hiring system differs from that traditionally implemented in Japan, which involves hiring of staff in groups at set times. 
This policy has a significant impact on element $b$ for creating an attractive nursing practice environment. It was shown that flexible hiring and placement of resources by the hospital based on a business plan allows operations to run more smoothly than the traditional hiring method and can lead to improved patient care.

Specific policies in this area include "flexible transfer considering the personal circumstances of nurses" and "a system for hiring emergency nurses to manage hospital operations."

In advanced information societies, results cannot be achieved when an organization is focused inwardly (Tao, 2005). If an organization is open, it will obtain the necessary information from outside, which will transform the organizational environment to achieve results in line with the external environment that can be extended outside the organization (Katz \& Kahn, 1966).

This policy has a significant impact on elements a, c, d, and e for creating an attractive nursing practice environment. An open system of HRM, using information and resources from outside the organization, has various benefits. For example, it engenders strong leadership in nursing managers, promotes collaboration and equality among hospital teams, spreads opportunities for career advancement, and enables nurses to be aware of organizational approval and their participation in the organization.

Specific policies include encouraging nurses "to participate in conferences and seminars outside the hospital" and inviting "lecturers (including those from outside the nursing field) from outside the hospital if they are the best fit for nurse training."

This policy has a significant impact on elements $b$ and e for creating an attractive nursing practice environment, which suggests that providing a system for nurses to acquire skills through career development is connected to quality assurance of patient care and creates an environment where nurses can experience awareness of organizational approval and their participation in the organization.

Herzberg (1966) discussed the demand for two types of people at work in the motivational factor/environmental factory theory. Salary is an environmental factor, and keeping up with it is required at all times. Hayashi (2008) reported that remuneration has a strong impact on the desire to stay in a job and is a factor that impacts career formation by nurses. The present study also emphasized the need for assurance of career advancement in an attractive nursing practice environment.

Specific policies in this area include "a leave of absence system that allows nurses to utilize training to enter graduate school or acquire certification" and "compensation that reflects nursing expertise."

A nurse:patient ratio of 7:1 had a significant impact on many policy elements and on the creation of an attractive nursing practice environment. Enhancement of manpower supports policy enhancement, quality assurance of patient care, and career advancement opportunities for nurses. One of the requirements in the "personnel policies and programs" item for magnet certification is personnel placement that promotes safe and healthy work environments. In this study, respondents considered that enhancement of manpower supports a safe and healthy work environment and is a method of creating an attractive nursing practice environment.

Because the subjects were nursing managers at hospitals nationwide with 300 or more beds, there are limits with respect to generalization of the results. In addition, PES-NWI is based on self-reporting by nursing managers. A survey of the current nursing practice environment should be performed in the future. 


\section{Conclusions}

A questionnaire was completed by 305 nursing managers and the results were used to assess the relationship between HRM policies of hospital nursing managers and the nursing practice environment from the perspective of "magnetism." Five policy elements were extracted: (1) personal career development and organizational development, (2) goal management and personnel evaluation, (3) flexible hiring and transfer, (4) promotion of external interactions, and (5) assurance of career development. In addition, five elements comprising an attractive nursing practice environment were extracted: (a) demonstration of powerful leadership by nursing managers, (b) quality assurance in providing patient care, (c) team collaboration and equality, (d) opportunities for career advancement, and (e) nurse participation in organizational approval and decision-making.

Moreover, it was shown that the nursing practice environment became increasingly attractive as more of these policy elements were implemented. The following points were identified: (1) Enhancement of personal career development. (2) Goal management and personnel evaluation that assure the quality of patient care and promote team collaboration. (3) Incorporating a flexible hiring and transfer structure based on a business plan. (4) Promoting external interactions to create an open organization. (5) Ensuring career development. (6) Supporting a safe and healthy nursing practice environment by enhancing manpower.

\section{Acknowledgments}

To use the Japanese version of the "Nursing work index practical environmental scale", the author directly obtained permission from its originator.

\section{References}

Brown, M., Metz, I., Cregan, C., \& Kulik, C. T. (2012). Irreconcilable differences? Strategic human resource management and employee well-being. Asia Pacific Journal of Human Resources, 47(3), 270-294.

Chiang, H. Y., \& Lin, S. Y. (2009). Psychometric testing of the Chinese version of nursing practice environment scale. Journal of Clinical Nursing, 18(6), 919-929.

Choi, E. H., Kim, E. K., \& Kim, P. B. (2018). Effects of the educational leadership of nursing unit managers on team effectiveness: mediating effects of organizational communication. Asian Nursing Research, 12(2), 99-105.

Drucker, P. F. (1954). The practice of management. New York: Harper \& Row.

Francis, H. \& Keegan, A. (2006). The changing face of HRM: In search of balance. Human Resource Management Journal, 16(3), 231-239.

Hayashi, Y. (2008). Career formation in nursing and factors that impact it. Japan Journal of Nursing Science, 28(1), 12-20. (in Japanese)

Herzberg, F. (1966). Work and the nature of the man. New York: Thomas Y. Crowell Co.

Hirai, S. (2002). Career development in nursing: Human resource management in times of change. Tokyo: Japanese Nursing Association Publishing Company.

Izukami, T. (2007). Nurses' work environment in Japan: a collaborative study with Linda H. Aiken. Kango Kenkyu (Japanese Journal of Nursing Research), 40(7), 575-586. (in Japanese)

Karimi, L., Cheng, C., Bartram, T., Leggat, S. G., \& Sarkeshik, S. (2005). The effects of emotional intelligence and stress-related presenteeism on nurses' well-being. Asia Pacific Journal of Human Resources, 53(3), 296-310.

Kashiwagi, Y. (2006). Awareness survey of nurse work satisfaction and career formation through implementing personnel evaluation systems. Proceedings of the Japanese Society of Nursing: Nursing Management, 36, 68-70. (in Japanese)

Katz, D. \& Kahn, R. L. (1966). The social psychology of organizations. New York: John Wiley. 
Kim, K. J., Yoo, M. S., \& Seo, E. J. (2018). Exploring the influence of nursing work environment and patient safety culture on missed nursing care in Korea. Asian Nursing Research, 12(2), 121-126.

Kramer, M. \& Hafner, L. P. (1989). Shared values: Impact on staff nurse job satisfaction and perceived productivity. Nursing Research, 38(3), 172-177.

Kramer, M. \& Schmalenberg, C. (2005). Revising the essentials of magnetism tool: There is more to adequate staffing than numbers. Journal of Nursing Administration, 35(4), 188-198.

Lake, E. T. (2002). Development of the practice environment scale of the nursing work index. Research in Nursing \& Health, 25(3), 176-188.

Lake, E. T. (2007). The nursing practice environment: Measurement and evidence. Medical Care Research and Review, 64(2 Suppl), 104S-122S.

Lammintakanen, J., Kivinen, T., \& Kinnunen, J. (2008). Human resource development in nursing: Views of nurse managers and nursing staff. Journal of Nursing Management, 16(5), 556-564.

McCusker, J., Dendukuri, N., Cardinal, L., Laplante, J., \& Bambonye, L. (2004). Nursing work environment and quality of care: Differences between units at the same hospital. International Journal of Health Care Quality Assurance Incorporating Leadership in Health Services, 17(6), 313-322.

Ogata, Y., Nagano, M., \& Akanuma, T. (2008). The practice environment scale of the nursing work index (PES-NWI). Chiba University Faculty of Nursing Bulletin, 30, 19-24. (in Japanese)

Schein, E. H. (1978). Career dynamics. Translated by Nimura, T. \& Miyoshi, K. (1991). Tokyo: Hakuto Shobo.

Shin, M. (2002). On overlapping white collar commitments. Mita Shougaku Kenkyu (Mita Business Review), 44(6), 117-143. (in Japanese)

Tao, M. (2005). Nursing management theory and reality from the standpoint of human resource theory. Tokyo: Iryou Bunkasha.

Tejima, M. and Ibe, T. (2009). Using human resources in nursing. Tokyo: Japanese Nursing Association Publishing Company.

Tyson, S. (1995). Human resources and business strategy: Towards a general theory of human resource management. London: Pitman.

Uchida, C., Miyaji, T., \& Iwahana, A. (2008). Nurse evaluations of a clinical ladder system. Proceedings of the Japanese Society of Nursing: Nursing Management, 38, 327-329. (in Japanese)

Watanabe, A. (2002). Human resource management strategies for nursing organizations: Environmental changes enveloping hospitals and issues of human resource management. Nursing Management, 12(9), 668-674. (in Japanese)

Yokoyama, T., Shigeta, K., \& Iwanade, K. (2005). Effects of implementing career development programs: Does self-efficacy of nurses change through career development programs? Nursing Management, 36, 9-11. (in Japanese)

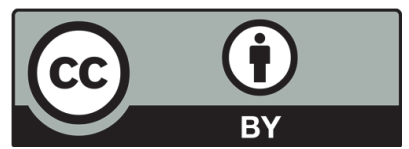

(C) 2019 by the authors; licensee Growing Science, Canada. This is an open access article distributed under the terms and conditions of the Creative Commons Attribution (CC-BY) license (http://creativecommons.org/licenses/by/4.0/). 